\title{
Permanent position
}

\author{
A lesson from history.
}

\section{John Gilbey}

After running out of postdoc money, and then running out of sofas to sleep on, it was a great relief to get offered work by the Institute. Only a short-term contract, obviously. Like everywhere else these days you need to be practically a Nobel laureate to get a permanent post.

Before we go any further, I should remind everyone that the Institute for Temporal Sciences - despite its reputation for secrecy - has nothing to do with time travel, except in the strictly linear sense of the term. It is really all to do with a sort of pan-spectral archaeology sucking swarms of ultra-fine contextual data from a historical artefact and building a holistic information structure that tells you everything from the history of its travel to the emotional health and genetic make-up of everyone who has handled it.

I've always enjoyed working nights: no interruptions, nobody hassles you, no idle chats at the Eats machine. You can just get in the lab and get the job done. Nice. The building, a low mushroom-shaped structure on the science park, watched me stump up to the door and decided not to call Security - which it sometimes did out of spite, or possibly boredom. It opened the main door and lit my way down the elegantly minimalist corridor towards my lab.

The space they'd given me was big - really big. But then, before practical room-temperature superconductors came along, the kit would have been the size of a power station, if you could have built it at all. Three months ago the lab was as stylish as the rest of the building - but all the hugely expensive systems had been installed by consultants, so everything worked exactly to specification while wholly failing to deliver what was needed. They recruited me to sort out the mess - and my time has been spent ripping stuff out, reinstalling, realigning and generally commissioning - so the floor is now stained with lubricant spills and burn marks, and the walls have gained markerscribbled lists of parameters, phone numbers and direction arrows.

While the coffee brewed I ran a system check and called up some grungy old rock as background noise. On my desk was the pile of samples for the night - all in sealed hi-tech plastic lunchboxes marked with a single barcode. Security was a hot topic in the Institute and I'd yet to see a single sheet of paper that wasn't 'Commercial In Confidence'.

Imagine my delight then, when I noticed that the seal on one of the boxes wasn't

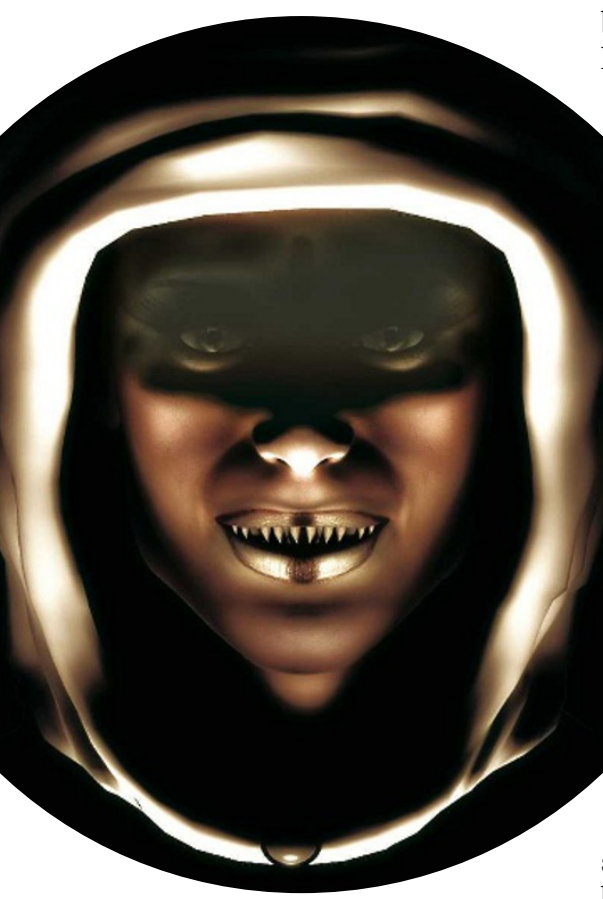

quite stuck down. After a crafty look round, I snuck a peek inside.

A single piece of ancient paper looked back at me, covered in not-quite-Cyrillic writing and carrying a woodcut of unsettlingly graphic violence. It depicted some sort of cloaked head honcho cheerfully supervising the bloody disassembly of a rather glum fellow by some enthusiastic henchmen. Not pleasant - but hey, that's history for you. Oddly disappointed - no jewels, no gold - I sealed up the box, locked all the samples into the purge tank and thought no more about it.

The message was waiting for me at the end of my shift - on paper, in an envelope no less. The Director and the Board wanted to see me the following evening to discuss my contract - which I hoped meant an extension and, who knows, maybe tenure. Bitterly resisting the temptation to go out and get completely lashed, I trotted off home and got some sleep. A smarter bloke would have wondered about the timing.

The boardroom was as expensively austere as the rest of the building; the formally gowned board members were typical old committee hands - little hair, less conversation and no obvious sense of humour. The Director welcomed me with an almost-smile and directed me to a chair. He told me how pleased they were with me, how much they valued my contribution and all the usual flannel - including a bit about my 'interest in the subject', which hinted that they knew about the sample.

Then he paused, looked at me squarely and said: "We want to offer you a permanent position - but before we discuss that, there are some things you must understand about the Institute. Our funding comes from a group that values its privacy - as you probably know. We are dedicated to the collection of important cultural information that was previously considered lost - to the great misfortune of our funders, who have been the subject of systematic and venal persecution as a result. You would be helping to right a great wrong - and would be amply rewarded."

I liked the sound of 'amply rewarded'. Sure, I had guessed that some band of well-resourced weirdos was behind the Institute - but for permanent money I'll work for anyone even moderately legal.

"Where do I sign?" I enthused, with a big grin. An admin person with a contract and a pen oozed up to my side. The contract ran to about 20 pages - I just flicked through and poised the nib over the last page.

"The contract is permanent, and in some senses irrevocable. I would encourage you to read it closely," intoned the Director courteously. I smiled to the crowd at the table. "Hey, I trust you," I beamed, and signed with a flourish.

With a sigh of corporate satisfaction, everyone in the room grinned openly. I looked with some shock from face to face - and finally at the impressive canine teeth of the Director. As he advanced towards me - gown flaring, jaws wide - I saw just how much he now resembled the figure in the woodcut, and realized that I probably should have read the small print.

John Gilbey is a writer and photographer who has held a number of short-term research contracts, although not in exactly these circumstances. 